\title{
Development and Evaluation of a Cognitive Training Application for Children With Learning Difficulties: A Design-Based Approach
}

\author{
Adel Shaban, Teesside University, UK \\ Victor Chang, Teesside University, UK \\ (iD) https://orcid.org/0000-0002-8012-5852 \\ Andrew Bingham, Teesside University, UK
}

\begin{abstract}
The studies targeting cognitive training via computerized applications focused on suggesting varied types of working memory (WM) tasks rather than offering those tasks in a user-friendly way or suggesting practical guidelines targeting the end-user. Therefore, the purpose of the current study is to adopt the design-based research method (DBR) to design, develop, and evaluate a cognitive training application in the light of a set of proposed guidelines. This developed application is targeting children with LDs at primary schools. The current study focused on end-user testing by evaluating the children's perceived experience during and after engagement in the application. The results showed that most of the children (86.5\%) perceived a good experience with the application, and their verbal and non-verbal WM performance improved significantly after the training period. A set of theoretical and practical implications derived from the study was embedded for future research.
\end{abstract}

\section{KEYWORDS}

Computerized Training, Design-Based Research, Game-Like, Learning Difficulties, User Experience, Working Memory

\section{INTRODUCTION}

In the mainstream classrooms in the United Kingdom, any pupil who needs additional support compared to his peers to succeed is categorized as having special education needs (SEN) (Department for Education-UK, 2016). In the United Kingdom and the United States, between $14 \%$ and 30\% of children at schools require extra support to learn (Department for Education-UK, 2018; McFarland et al., 2019). Children and young people with SEN often have learning difficulties (LDs) that hold them from learning compared to their peers. Learning difficulties do not affect general intellect, although they can cause a person to face problems in a traditional classroom setting (Mencap, 2021). Thus, children with LDs have normal intelligence, but this is not matched with their low learning potential or scholastic achievement (Chen et al., 2017).

Recently, WM deficit has been considered a significant contributing factor of LDs (Peng \& Fuchs, 2016; Zhang et al., 2018). For instance, a meta-analysis of 29 studies revealed that all the 
groups with LDs (with reading difficulties, mathematics difficulties, or both) showed deficits either in verbal or numerical WM (Peng \& Fuchs, 2016). In the current study, children with LDs refer to those children in the mainstream classrooms who have a poor WM capacity, which hinders their learning process, and as a result, they have lower academic achievements compared to their peers, irrespective of their normal intelligence.

Working memory (WM) is the capability of the brain to retain and manipulate some information for a short time. According to the integrated model of Baddeley and Hitch (Baddeley, 2000), WM consists of four sub-systems: the main system (the central executive) and three slaving systems: the phonological loop, the visuospatial sketchpad, and the episodic buffer. The central executive is an attentional control system responsible for allocating attention within the WM system via focusing, dividing, and switching attention; and three slaving systems: the phonological loop which is taking charge of holding and manipulating sounds and speech; the visuospatial system, which is performing a similar function with non-verbal materials; and the episodic buffer which is acting as a coordinator to link between the various WM components and long-term memory (Baddeley, 2000). Children with LDs often have a limited WM capacity, this means they fail to meet the required amount of information needed to be processed and held while learning new skills. As soon as those children are able to overcome their WM limits, they would be able to learn as effectively as others (Gupta \& Sharma, 2017).

Research has suggested that WM capacity can be enhanced by intensive cognitive training because its underlying neural systems remain flexible throughout the lifespan (Klingberg et al., 2005; Mahncke et al., 2006). The cognitive training focuses on enhancing the trainee's WM capacity mainly by expanding the extent of information that can be kept and manipulated in the WM components (Wong et al., 2014). It is recommended that WM training should take place for 20 days in a 4 to 7-week period with sessions of approximately 30 - 45 min per day (Wong et al., 2014).

However, cognitive tasks usually require effort and can be considered repetitive and frustrating, which often impact negatively on participant engagement. This, thereby, might negatively influence the quality of the collected data and/or reduce the effect of the intended intervention (Lumsden et al., 2016). Regarding tackling this problem, using game elements as a vehicle to provide learning and cognitive training, can motivate and engage participants (Dichev \& Dicheva, 2017; Lumsden et al., 2016) because of the pleasure and the excitement that these activities offer. Consequently, researchers such as Ninaus et al. (2015) embedded a group of specific game elements, e.g., progression bars, setting, and points, into one of the conventional WM training systems to motivate a group of university students; the results showed that the performance, as well as efficiency in a WM task, could be improved. By contrast, other studies showed that applying different game elements could increase cognitive load levels via inducing unwanted stress or bringing new cognitive demands. These game elements could also divert the trainees from the main purpose (Katz et al., 2014; Nebel et al., 2016; Turan et al., 2016). As a result, incorporating some game elements into the applications designed to train the WM of children with LDs should be applied with caution, considering their characteristics and needs, not overloading WM, or burdening their cognitive abilities.

To our knowledge, there is little research in training programs to train WM of children with LDs, and the majority of the studies targeting WM training include children with Attention deficit hyperactivity disorder (ADHD) (Peijnenborgh et al., 2016). Boyle et al. (2011) recommended that future studies target various categories of LDs, utilizing various training programs (e.g., gaming environment) due to the growing prevalence rates in LDs.

In addition to that, the studies targeting cognitive training, which either developed computerized WM training tasks and/or embedded game elements to the training tasks, focused on suggesting varied types of WM's tasks rather than offering those tasks in a user-friendly way or suggesting practical guidelines targeting the end-user. A clear example of that is the results of a meta-analysis of 25 studies (Sinnari, 2019). In this study, Sinnari (2019) suggested that to design an effective WM training for children with ADHD, it is better to use varied tasks to train the WM components such 
as visuospatial WM tasks (e.g., object sorting), and verbal WM tasks (e.g., recalling a sequence of objects). A total of 25 studies offered different types of WM tasks, and none of them focused on how those tasks could be designed in the light of guidelines based on a scientific design theory.

Furthermore, there is little research about the evaluation of the cognitive training applications regarding the user experience, particularly for children with LDs. For example, Marcelle et al. (2018) revealed that COGMED, which is considered to be the most common commercial WM training program, was established by "leading neuroscientists" employing a top-down expert-driven method, and none of the end-user validation research was implemented to assess the trainees' experience. Marcelle et al. (2018) also indicated the significance of active end-user participation while developing cognitive applications, which can avoid the deployment of unbearable training models. Similarly, Abdou \& Jasimuddin (2020) indicated that involving the target users in the development process may positively impact the effective development and behavioral intentions using the technology. For instance, the ease and satisfaction of using the electronic system positively affect the acceptance of that system.

Therefore, the current study adopted the design based-research method (DBR) to systematically design, develop, evaluate, and refine a cognitive training application targeting children with LDs in the light of a set of practical guidelines developed by the researchers that can be used by other researchers as a guide while designing such applications. The developed application is bilingual (Arabic and English) and is considered a pioneer brain game in Arabic counties. The application is also free of charge, contrary to current WM commercial programs such as COGMED, which costs $\$ 1035$ per child (Roberts et al., 2016). Being the application bilingual could facilitate training the cognitive abilities of a wide range of children with special educational needs, whether in the eastern or western countries via the URL: http://www.wm-app.net/welcome.aspx.

Finally, the present study focused on end-user testing, where the children's perceived experience was evaluated during and after engagement in the application.

Hence, the aims of this study are to:

- adopting the DBR approach to develop a cognitive training application targeting children with LDs.

- Evaluating the perceived experience of the target users and their WM performance.

\section{METHOD}

\subsection{Research Design}

The current study utilizes a design-based research approach to design, develop, and evaluate a cognitive training application targeting children with LDs to improve their WM capacity.

Design-based research (DBR) is a methodological framework aimed to help and guide the researchers while developing or designing interventions. The framework is utilized to systematically assess the efficacy of the embraced interventions to tackle real and complicated learning problems and validate or enrich the existing theories (Jen et al., 2015; Kennedy-Clark, 2013). Once this study focuses on developing and evaluating the perceived experience of a cognitive training application through iterative processes to detect both the theoretical and practical implications of the cognitive training applications' design, the DBR will be ideal for addressing the purpose of this study.

DBR researchers often assess/test the effectiveness of multiple or complex interventions. Therefore, DBR researchers usually combine quantitative and qualitative approaches to gather the required data to refine the questions of their study (Brown, 1992; Jen et al., 2015). Consequently, in the present study, various qualitative and quantitative approaches were adopted to assess the perceived experience of the target users with the developed application.

In DBR, the intervention process is iterative and performed following a cycle of a couple of stages of design, implementation, and feedback from implementation. Then flows into subsequent 
cycles of (re)design, (re) implementation, and refinement (Jen et al., 2015; Kennedy-Clark, 2013). Therefore, in the current study, two design cycles were embraced, shown in Figure 1, to design, develop, evaluate, and refine the cognitive training application.

\section{Figure 1. The adopted DBR framework in this study}

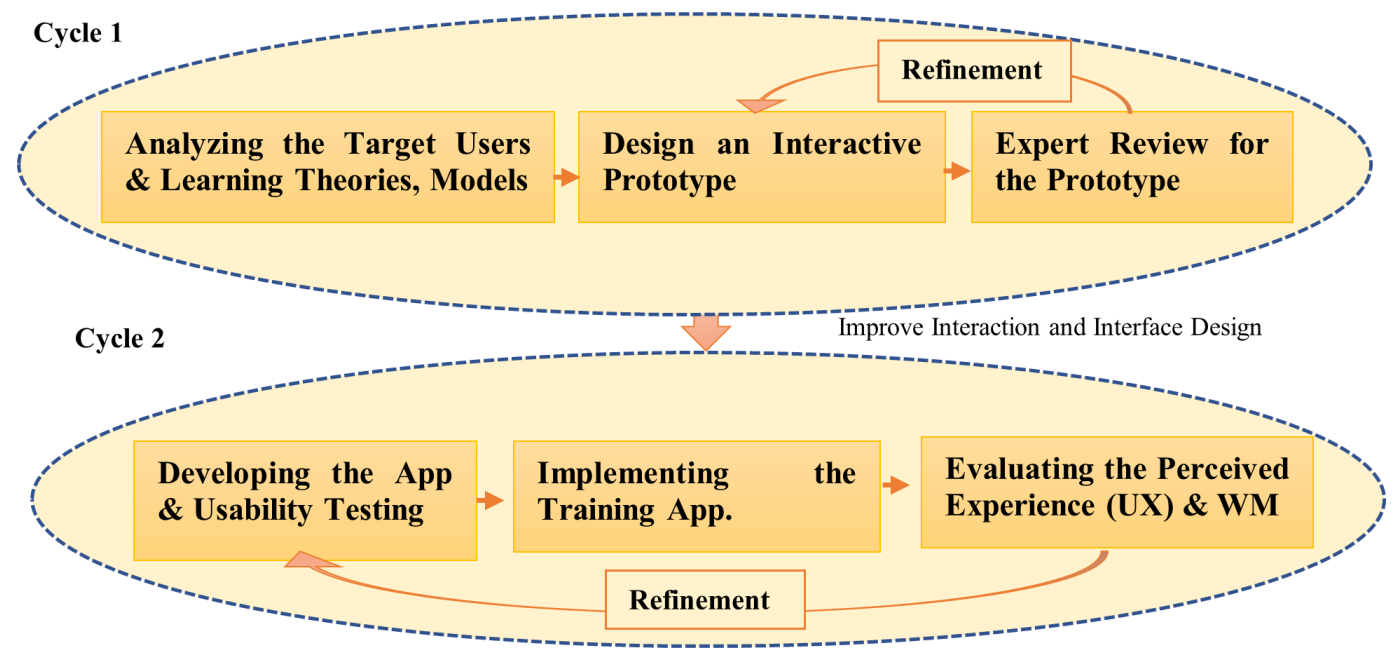

The first iteration focused on analyzing the target users' characteristics and the learning theories, designing an interactive prototype, and performing a heuristic evaluation to get feedback to improve the prototype's usability.

The second iteration covered developing and applying the training application on a sample group of children diagnosed as having LDs to assess their perceived experience during the training period and evaluate the impact of the training application on improving children's WM performance.

\subsection{Participant Recruitment}

In the first iteration, twelve experts participated in doing the heuristic evaluation/expert review for the designed prototype. The twelve experts were selected from a range of specialisms: accessibility and UX consultants (3 reviewers), experts in learning disabilities ( 3 reviewers), instructional technologists ( 3 reviewers), HCI and cognitive psychologist (one reviewer), educational psychologist (one reviewer), and web developer (one reviewer). Ten reviewers were interviewed (two were interviewed face-to-face, and eight via skype) to explain the prototype and answer their questions. Only two of the reviewers were contacted through e-mail.

Regarding the second iteration, a sample of children with LDs, aged 8-9, from an Egyptian primary school participated in the second cycle. Those children were selected as they have lower academic achievement, irrespective of their normal intelligence, and they have a poor WM capacity. Therefore, the following tests were performed:

\section{- Academic Tests:}

Two academic tests were developed, then statistically standardized before being applied. The two tests (Arabic and Math) were used to pinpoint the students who show poor academic achievement 
( $<25$ th percentile) in Arabic and/or Math compared to other students in their classes. 26 out of 55 students in the 3rd grade were chosen, and they agreed to participate in the study.

- Intelligence Quotient (IQ) Test:

The abbreviated battery of the fifth edition of the Stanford-Binet intelligence scales was used to test the sample IQ (Farag, 2011). 5 out of 26 students did not agree to complete the full diagnosis process, so they were excluded. The students who showed average intelligence (85-110) were chosen and participated in the next screening stage; only 17 out of 21 students met this criterion.

- Working Memory tests:

Verbal (memory for sentences and last word) and non-verbal working memory tests (delayed response and block span tasks) of the Stanford-Binet Intelligence Scale (Fifth Edition) were performed on the 17 students to evaluate their working memory capacity. The results indicated that 16 of 17 students scored $<50 \%$ in verbal and non-verbal tests, and therefore were selected and agreed to engage with the WM training application.

Consequently, 16 children were recognized as having LDs depending on the former criteria: lower level of academic achievement, with average intelligence on the IQ scale (85-110), and with scores $<50 \%$ in the working memory tests. Finally, those 16 students initially engaged in the training process followed the evaluation process with parental consent.

Three out of the sixteen children attended the first three training sessions and could not complete the training. The reason behind that the training was performed after finishing the scholastic term and thereby the children's parents could not take their children to the school daily, and they also did not have internet access to the training from home. Finally, one more child attended only eight training sessions intermittently. Thus, he/she was excluded. Consequently, twelve out of sixteen children completed the whole training and participated in the evaluation process as well.

\subsection{Procedures}

The procedures of the design-based research approach employed in the current study are described as follows.

\subsubsection{First Iteration}

The first iteration covered the following steps:

\subsection{Needs Analysis and Learning Theories:}

Xanthidis \& Xanthidou (2021) indicated the significance of identifying the stakeholders' interests, needs, characteristics, and expectations while developing the electronic systems. Hence, the first step was analyzing the children's needs, characteristics, and the existing learning theories, as follow:

Research has shown that learning difficulties are closely associated with a WM deficiency (e.g. (Maehler \& Schuchardt, 2016; Peng \& Fuchs, 2016; Zhang et al., 2018)). Furthermore, these children also often have a lower level of motivation (Saputra, 2015; Zisimopoulos \& Galanaki, 2009). Thus, improving their limited working memory capacity by designing engaging and motivational training applications (Melby-Lervåg \& Hulme, 2013; Saputra, 2015), and developing learning environments that minimize the load on students' working memory (the cognitive overload that might hamper learning) (MacCormack \& Matheson, 2015) would benefit in lessening the difficulties faced during the learning process (Chen et al., 2017; Gathercole, 2009).

Alloway et al. (2009) indicated that children with poor WM capacity have short attention spans, a high grade of distractibility, and difficulties creating new solutions to problems. Similarly, Gathercole 
(2009) revealed that it is difficult for those children to follow multi-step instructions or combine processing with storage, and they show poor writing and reading capabilities. These characteristics were taken into consideration during analyzing the learning theories and designing the prototype's activity.

In order to meet the needs and the characteristics of those children, a thorough review of the literature on the principles of cognitive load theory and its frameworks, Human-Computer Interaction (HCI) concepts (e.g., usability and user experience principles), and a set of games techniques has been done to propose a set of 15 guidelines, as shown in Table 1, to design an interactive cognitive prototype. The rationale behind choosing those guidelines is the following:

- Five guidelines covering the learning environment (interface and interaction) were extracted to design a simple interface, minimize the distraction level, and exclude non-essential material.

- Six guidelines covering the tasks (learning materials) were derived to simplify the presented WM activities that suit the limited WM capacity of the children.

- Four guidelines covering the target users were extracted to help, motivate, and make users managing their applications, thereby improve the children's experience with the training application.

In order to extract a set of activities to training the WM components, the integrated model of Baddeley and Hitch (Baddeley, 2000) was adopted. The adopted WM model proposes that WM includes four components: a key system (the central executive) along with three slaving systems: the phonological loop, the visuospatial sketchpad, and the episodic buffer. According to the adopted model (Swanson \& Sáez, 2003), a WM training application typically covers systematic and thorough training on a set of standard tasks that target the WM components. These include phonological tasks (e.g., forward digit span, letter-number sequence, and letter span task); visuospatial tasks (e.g., word location, dot location task), and central executive tasks (e.g., operation - word span, two-back, and dot matrix task). Hence, the current training focuses on enhancing the trainee's WM capacity by expanding the amount of information that can be kept and manipulated in the WM components with engaging and motivating ways (Wong et al., 2014).

\subsubsection{Design an interactive prototype.}

Based on the suggested guidelines in Table 1 and the integrated model of Baddeley and Hitch (Baddeley, 2000), six short activities (Numbers, Map, Letters, Hidden Objects, Compass, and Faces) were suggested to train the WM capacity of the target users. A set of specific game elements (a meaningful story, points, levels, incentives and rewards, virtual competitor, badges, virtual helper, and progress reports) was used to make the suggested activities more game-like. Those game elements were embedded in the prototype with caution to meet the characteristics of those children and motivate them during the training period without overloading their limited WM capacity.

Finally, an interactive prototype was designed using the UXPin Platform. The interactive cognitive prototype is presented in the form of a meaningful story, "The Treasure Hunt," with six short activities, as shown in Table 2. A virtual competitor (the pirate) was applied rather than using external competition with others. The trainee plays against the pirate to get the treasure by collecting more stars via correct responses; the goal is to defeat the pirate and get the treasure. The first two levels of each activity were designed as interactive to declare the idea of the prototype activities. However, the interactive prototype was not fully functional for all aspects of the application (e.g., it does not support vocal sounds). Consequently, some hints and comments were used to describe the vocal sounds and audio feedback.

\subsubsection{Expert Review for the Prototype}

An evaluation of the prototype was performed to assess the appropriateness of the suggested guidelines for the application type and the target users generally and obtain feedback to improve the 
Table 1. The proposed guidelines for designing the training application.

\begin{tabular}{|c|c|}
\hline Guideline & How was it applied? \\
\hline \multicolumn{2}{|c|}{ Guidelines for designing the learning environment (application interface design) } \\
\hline $\begin{array}{l}\text { Use consistent elements throughout the application } \\
\text { (e.g., characters, colors, backgrounds, buttons, icons } \\
\text { etc.). }\end{array}$ & $\begin{array}{l}\text { All the prototype's backgrounds, characters, buttons, icons were designed to be related to the story } \\
\text { of a treasure hunt. For instance, using the island, water, pirate, parrot, pirate's tools, fish, ships, etc., } \\
\text { was acceptable. }\end{array}$ \\
\hline $\begin{array}{l}\text { Minimize distracting elements (e.g., movement, } \\
\text { scrolling, background music, the competition time) in } \\
\text { the application. }\end{array}$ & $\begin{array}{l}\text { The user interface was designed to be simple in navigation with a limited number of icons and } \\
\text { animation. }\end{array}$ \\
\hline $\begin{array}{l}\text { In case of providing help, the helper/guide should have } \\
\text { a user-friendly tone and uses affirmative language with } \\
\text { the familiar word. }\end{array}$ & $\begin{array}{l}\text { The parrot (virtual helper) used a human voice with a friendly tone to be familiar, clear, and } \\
\text { understandable for the children. }\end{array}$ \\
\hline $\begin{array}{l}\text { Alert users to errors or possible errors e.g., before the } \\
\text { exit or cancel orders. }\end{array}$ & Readable messages are provided to confirm actions (e.g. quit, and home). \\
\hline $\begin{array}{l}\text { Use sufficient contrast between the text and } \\
\text { background, and the text's font should be clear and } \\
\text { readable (e.g., using sans-serif fonts such as Arial, } \\
\text { Verdana, Helvetica and Tahoma) }\end{array}$ & The family fonts of sans-serif fonts were used in the prototype to be clear and readable. \\
\hline \multicolumn{2}{|l|}{ Guidelines for designing the learning materials } \\
\hline $\begin{array}{l}\text { Presenting the working memory activities in the form } \\
\text { of a meaningful story was recommended. }\end{array}$ & $\begin{array}{l}\text { The prototype, "The Treasure Hunt" represents a well-known meaningful story including six short } \\
\text { activities to help the child to get the treasure, as shown in Table } 2 \text {. }\end{array}$ \\
\hline $\begin{array}{l}\text { Use a range of activities to train different components } \\
\text { of WM (such as verbal, visual, and central executive } \\
\text { activities) }\end{array}$ & $\begin{array}{l}\text { The prototype consists of six activities: Faces and Map activities to train the visuospatial component, } \\
\text { Hidden Objects' activity to train the visuospatial and central executive components, Numbers activity } \\
\text { to train the verbal component, and Letters and Compass activities to train the verbal and central } \\
\text { executive components. }\end{array}$ \\
\hline $\begin{array}{l}\text { The application's activities are short, simple, have their } \\
\text { own goals, and the difficulty level of each activity } \\
\text { increases while the trainee progresses to higher levels. }\end{array}$ & $\begin{array}{l}\text { The prototype consists of six short activities (below } 5 \text { minutes in duration) to improve children's } \\
\text { WM components such as numbers, Letters, Faces, Map, and Hidden Objects, compass, as shown in } \\
\text { Table } 2 \text {. } \\
\text { Points, presented as golden stars, were embedded to enhance children's enjoyment. The trainee could } \\
\text { get a gold star if he achieved a correct response (level). The trainee should earn at least a score of } \\
>80 \% \text { (which is equal to around } 24 / 30 \text { golden stars in the } 6 \text { activities) to get the treasure. } \\
\text { Each activity involves five levels. The level of difficulty increases as the child progresses from the } \\
\text { first to the fifth level. }\end{array}$ \\
\hline $\begin{array}{l}\text { Minimize text input and rely on spoken (e.g., providing } \\
\text { a narration option) and visual inputs (e.g., using a } \\
\text { visual password). }\end{array}$ & $\begin{array}{l}\text { A visual password was used to minimize the text input and the reading overload. The password } \\
\text { consists of a group of } 9 \text { images. The user can select three images to form his own password. In order } \\
\text { to enhance accessibility, a narration option was provided to turn all the icons, buttons, and main } \\
\text { elements readable while doing mouse hover. }\end{array}$ \\
\hline $\begin{array}{l}\text { Present a summarizing report regarding the trainee's } \\
\text { achievement by the end of each activity and every } \\
\text { session or set of activities. }\end{array}$ & $\begin{array}{l}\text { A concise report regarding the user's achievement is shown after each activity, and a final report at } \\
\text { the end of each training session was provided to help the child celebrate with getting the treasure (if } \\
\text { the child combats the pirate). } \\
\text { Badges icon was used on the home page, as a reward, to the one who got the treasure, either the child } \\
\text { or the pirate. }\end{array}$ \\
\hline $\begin{array}{l}\text { Highlight the most important elements, such as the } \\
\text { options chosen by the users. }\end{array}$ & When a set of buttons were read, images were highlighted to attract the children's attention. \\
\hline \multicolumn{2}{|l|}{ Proposed user guidelines } \\
\hline $\begin{array}{l}\text { Allow the user to be in control of the application via } \\
\text { support elements, self-pace progression, navigation. }\end{array}$ & $\begin{array}{l}\text { The user can choose the application's language (Arabic or English), select any activity/game, get } \\
\text { immediate help throughout the application, and progress in self-paced activities. }\end{array}$ \\
\hline $\begin{array}{l}\text { The application provides constructive feedback } \\
\text { (positive in tone and short) on a user's actions for } \\
\text { correct and incorrect answers. }\end{array}$ & $\begin{array}{l}\text { Constructive feedback (audio) for both correct responses (e.g., "excellent", "good work", "well } \\
\text { done"), and incorrect ones (e.g. "You can get it next time", "keep trying", and "you tried very hard") } \\
\text { can also be included. }\end{array}$ \\
\hline $\begin{array}{l}\text { Provide the users with help (either auditory or visual) } \\
\text { whenever they need it throughout the application. }\end{array}$ & $\begin{array}{l}\text { A virtual assistant (a parrot) was provided to help the users throughout the application and presents } \\
\text { an emulated example prior to each activity. }\end{array}$ \\
\hline $\begin{array}{l}\text { The application should be intrinsically motivating, such } \\
\text { as being in the form of a contest between the child and } \\
\text { a virtual competitor. }\end{array}$ & $\begin{array}{l}\text { The application is designed in the form of a contest between the trainee and the virtual competitor } \\
\text { (the pirate). The user plays against the pirate to win the treasure via correct responses. Therefore, the } \\
\text { goal is to beat the pirate and get the treasure at every session (daily internal competition). }\end{array}$ \\
\hline
\end{tabular}


Table 2. The prototype's activities

\begin{tabular}{|c|c|c|c|}
\hline Activity & Description & Interface & $\begin{array}{c}\text { Targeted WM component } \\
\text { \& task's type }\end{array}$ \\
\hline Faces & $\begin{array}{l}\text { A pirate face is shown to the child. The } \\
\text { child should memorize it before some of } \\
\text { its features are being hidden then he will } \\
\text { be asked to choose the right features to } \\
\text { complete the face of the pirate. }\end{array}$ & (m) & $\begin{array}{l}\text { Visuospatial component } \\
\& \\
\text { (Pattern recognition) }\end{array}$ \\
\hline Map & $\begin{array}{l}\text { A group of treasure chests will appear on } \\
\text { a map. The child should memorize their } \\
\text { locations before being hidden, and then he } \\
\text { should click on the locations correctly. }\end{array}$ & $0 \sqrt{c}$ & $\begin{array}{l}\text { Visuospatial component } \\
\& \\
\text { (Remembering the location } \\
\text { and order of objects) }\end{array}$ \\
\hline $\begin{array}{l}\text { Hidden } \\
\text { Objects }\end{array}$ & $\begin{array}{l}\text { A set of images hanging on a rope will } \\
\text { appear in a particular order. The child should } \\
\text { memorize them before being hidden and } \\
\text { swapped. The child then should select them } \\
\text { correctly. }\end{array}$ & $\sqrt{10}$ & $\begin{array}{l}\text { Visuospatial and central } \\
\text { executive component } \\
\& \\
\text { (Recalling a sequence of } \\
\text { objects) }\end{array}$ \\
\hline Numbers & $\begin{array}{l}\text { A set of numbers will be heard by the child. } \\
\text { He should memorize them, then select them } \\
\text { in order (from the smallest to the biggest) }\end{array}$ & & $\begin{array}{l}\text { Phonological loop (verbal) } \\
\text { component } \\
\& \\
\text { (Object sorting) }\end{array}$ \\
\hline Letters & $\begin{array}{l}\text { The trainee should hear and memorize a } \\
\text { group of letters then select them in reverse } \\
\text { order. }\end{array}$ & 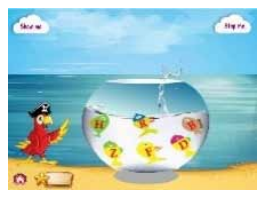 & $\begin{array}{l}\text { Phonological loop (verbal) } \\
\text { and central executive } \\
\text { component } \\
\& \\
\text { (Backward object verbal } \\
\text { recall) }\end{array}$ \\
\hline Compass & $\begin{array}{l}\text { The trainee should memorize one of the four } \\
\text { directions he heard, and then he will see a } \\
\text { compass. He will be asked to choose (Yes, or } \\
\text { No) according to if the direction matches the } \\
\text { compass or not and then he should click on } \\
\text { that direction he has just heard as it will be } \\
\text { shown on the screen. }\end{array}$ & & $\begin{array}{l}\text { Phonological loop (verbal) } \\
\text { and central executive } \\
\text { component } \\
\& \\
\text { (Verbal recall and } \\
\text { comparison) }\end{array}$ \\
\hline
\end{tabular}

usability of the final application for children with LDs. Twelve experts participated in the evaluation process via an online survey. The survey consisted of 24 questions based on the 15 guidelines with responses on the standard 5-point Likert scale (Strongly Disagree $=1$ credit, Disagree $=2$ credits, Neutral $=3$ credits, Agree $=4$ credits, Strongly Agree $=5$ credits) along with free-text responses. The respondents were provided with a link to the interactive prototype and were asked to review the designed prototype against the guidelines to identify to what extent the designed prototype structure was suitable for the target users.

The reviewer's suggestions and amendments were taken into consideration while developing the application in the second iteration. 


\subsubsection{Second Iteration}

\subsubsection{Development of the application and testing its usability.}

The training application was developed as a web-based application consisting of six fully functional activities to train different WM components based on the designed interactive prototype and its evaluation outcomes. After finishing the development process of the application, it becomes accessible for both the trainer and the target users using the following URL (http://www.wm-app.net/welcome. aspx).

Abdou \& Jasimuddin (2020) demonstrated that there is a positive relationship between the degree of ease associated with the use of the developed technology and the behavioral intention to use that technology. Therefore, in this paper, the researchers developed usability testing to ensure that the developed application is easy to use and functional. The usability user test seeks to measure the three usability components: the capability of the child to finish a task completely (effectiveness), smoothly (efficiency), and enjoyably (the level of user satisfaction). Nielsen (2012) revealed that "a usability test carried out by only five users will find out $85 \%$ of the usability problems". Hence, a group of five children aged 8-9 years, having LDs, participated in the usability testing of the developed application.

The researchers prepared two observation checklists covering a set of tasks (for the login and logout and for playing the application activities/games) to assess the effectiveness and the efficiency within the application. The level of satisfaction was measured using a questionnaire applied to children after they finished playing the application.

The average of the three usability components: the effectiveness, efficiency, and satisfaction rates, were calculated to measure the overall usability.

The results showed a set of usability issues that were tackled before implementing the developed application.

\subsubsection{Implementation of the developed application.}

Targeting at the adopted WM model (Baddeley, 2000), WM training takes place for 20 days in a 4 to 7-week period with sessions of approximately 30 - 45 min per day (Wong et al., 2014). In the present study, each trainee in the experimental group (12 out of 16 children) took part in daily training, lasting from 20 to 35 minutes a day, 5 days a week from the $11^{\text {th }}$ of April to the $16^{\text {th }}$ of May (roughly 5 weeks) - a total of 27 sessions. Each child also participated in the process of evaluation prior to, through, and after the training. The training occurs at a computer lab in one of the primary schools in Egypt where there is internet access. The procedures of the study were approved by the Ethical Committee of Fayoum University-Egypt with written consent from the parents, and the children participated voluntarily.

\subsubsection{Evaluating the Perceived Experience (UX) \& WM Performance}

A usability survey (qualitative and quantitative) and an unstructured observation (qualitative) was employed to assess the trainee's perceived experience while engaging with the application over a training period of five weeks:

\section{Usability Survey}

The usability survey (closed and open-ended) assesses the trainees' experience generally with the application, particularly with the embedded game elements from the end users' perspective.

\section{Closed-Ended Questionnaire}

This part of the questionnaire initially consisted of 16 items (closed-ended) created by the researcher in the light of the suggested guidelines for developing the current application (see Table 1), and the examples given in the studies of (Nielsen, 2000; Seo \& Woo, 2010). The trainees (one-to-one) were 
required to rate the questions on a standard 3-point Likert scale ( $1=$ Disagree, $2=$ Neutral, $3=$ Agree), or they could choose one of 3 smiley faces.

\section{Interview-Based Questionnaire}

This part covered 5 items (open-ended) developed by the researcher in light of the examples shown in (Seo \& Woo, 2010) usability study. In the interview, all the trainees were inquired, on an individual basis, three questions regarding their perceived experience with the developed application such as "what games do you like to play? And Why?", "what are the games you do not like to play? And Why?", and "What do you like most about the treasure application?". Additionally, 2 extra questions about their preferred alterations and suggestions about the application were given. Finally, a good opportunity was given to the trainees to talk about their replies and recommendations regarding the application with the researchers.

\section{Unstructured Observation}

The unstructured observation method was used to observe how every child engaged with the application to evaluate the perceived experience. Over the training period, all the trainees were observed and monitored to assess and identify the activities they liked to play and opted to begin the sessions with; the activities they did not like and deferred playing until last; the children's responses and reactions on different aspects of the application; and their enthusiasm or hesitancy to complete the training. The competition between the trainees and the pirate (virtual competitor), and their feeling (positive/ negative) regarding the application were also observed and documented. Finally, the trainer created a report about every child by the end of the training.

\subsubsection{Evaluating working memory performance:}

The verbal and non-verbal working memory tests of the Stanford-Binet Intelligence Scale (Fifth Edition) were applied before and after the training period (as pre and post-tests) to assess the children's working memory performance before and after the training.

\section{THE RESULTS}

The results of evaluating the interactive prototype, usability user testing, evaluation of the entire perceived experience with the application, and the WM performance will be discussed.

\subsection{Expert Review/Heuristic Evaluation of the Prototype}

The survey showed a high-reliability degree, with an Alpha Cronbach score of 0.873 , which suggests that the survey is consistent and stable in assessing the application prototype.

Reviewers generally agreed that the application prototype met the suggested guidelines, at $84.6 \%$. The responses produced a mean value (M) of 4.23 out of 5 with a standard deviation (SD) of 0.92 for all survey items.

In detail, the reviewers strongly agreed that the prototype application supported the users with the required help and feedback at any anytime throughout the prototype, and the user can easily navigate the throughout prototype. Furthermore, the reviewers strongly agreed that the prototype graphics are appealing, the prototype's elements are consistent, simple, readable, and familiar for users.

Additionally, the reviewers provided a set of qualitative feedback that will contribute to improvements in the final application:

"The letters activity should be simpler (the letters are too much)." 
Therefore, the letters displayed in the aquarium will be reduced from 9 to 6 letters (see Figure 2(A)).

"Presenting images in the Hidden Objects activity needs to be visualized to facilitate remembering it."

Therefore, the presentation of images in the Hidden Objects activity will be changed in the final application such that instead of the images being hidden, they will be presented side by side with the required image highlighted (see Figure 2(B)).

"Use fewer colors and fewer details in the picture on the interface page."

Therefore, the images and icons were revised and simplified to reduce extraneous visual information (e.g. see Figure 2(C), Figure 2(D)).

How can you ensure that the trainees have the same training chances (limit the frequency of every game per day and the whole training)?

Therefore, the final application will have a login through a visual password at the beginning to control the daily access. Additionally, it will be disabled for 12 hours on completion of each activity (see Figure 2(E)).

Figure 2. Improvements in the final application

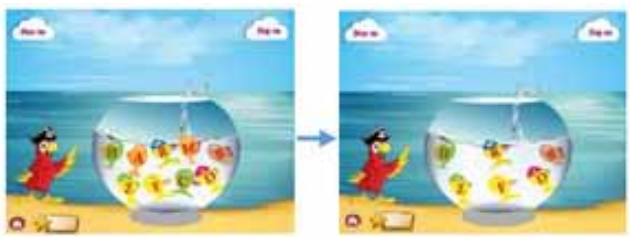

A) Letters game before and after.

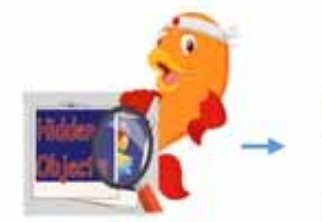

C) Tools game icons before and after.

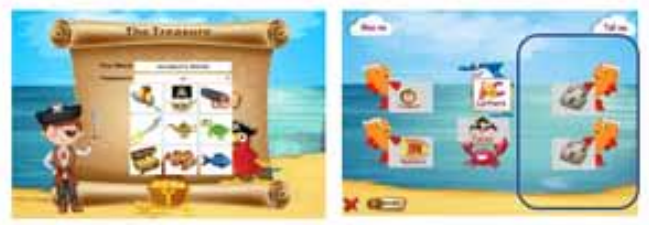

E) Visual password and disabled games icon.

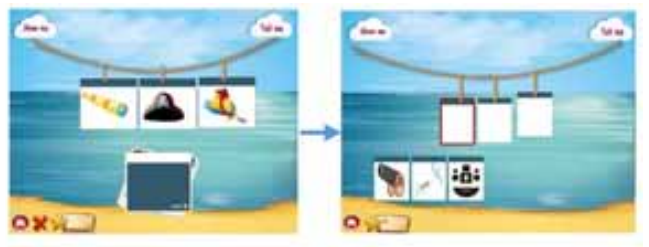

B) Tools game before and after.

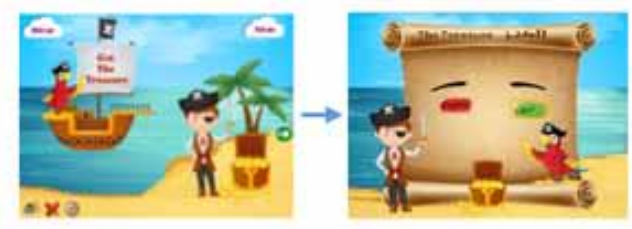

D) Home interface before and after.

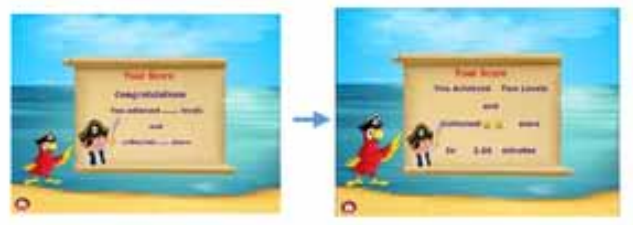

F) Activity report with time before and after.

"What about the time of every session? I did not find a clock for getting me aware of time". 
Therefore, the addition of a time counter may increase anxiety; therefore, the progression in all games is self-paced. However, in the final application, the activity report will indicate how long the child has spent playing the activity to encourage them to complete it faster on subsequent attempts (see Figure 2(F)).

"I think the compass activity needs more revision, some students with LDs can be easily confused in detecting directions, and this may explain their wrong responses more than working memory".

Therefore, pre-training about directions will be provided to familiarize the child through a simulation at the beginning of the compass activity, which can also be accessed at any point during the activity (through the interactive helper - the parrot).

Finally, the reviewers acknowledge that "the prototype application has been designed in an ageappropriate manner"; and "the prototype provides a clear mental image about the final application".

\subsection{Usability User Testing}

After developing the training application, the data collected from applying the usability user test was analyzed to calculate the overall usability of the application, as follows:

\section{Effectiveness:}

Table 3. The results of analyzing the effectiveness, efficiency, and satisfaction.

\begin{tabular}{|c|c|c|c|c|c|c|c|c|c|}
\hline & \multicolumn{3}{|c|}{ Effectiveness (12 items) } & \multicolumn{3}{|c|}{ Efficiency (14 items) } & \multicolumn{3}{|c|}{ Satisfaction (5 items) } \\
\hline & Success & Partial success & failure & Success & $\begin{array}{l}\text { Partial } \\
\text { success }\end{array}$ & failure & Agree & Neutral & Disagree \\
\hline Child 1 & 8 & 4 & 0 & 13 & 1 & 0 & 5 & 0 & 0 \\
\hline Child 2 & 9 & 3 & 0 & 8 & 4 & 2 & 5 & 0 & 0 \\
\hline Child 3 & 8 & 3 & 1 & 9 & 3 & 2 & 5 & 0 & 0 \\
\hline Child 4 & 11 & 1 & 0 & 11 & 3 & 0 & 5 & 0 & 0 \\
\hline Child 5 & 10 & 2 & 0 & 12 & 1 & 1 & 5 & 0 & 0 \\
\hline Subtotal & 46 & 13 & 1 & 53 & 12 & 5 & $25 \times 3=75$ & 0 & 0 \\
\hline
\end{tabular}

The observation checklist of the effectiveness consists of 12 items with 5 attempts per item, totaling 60 items attempts, as shown in Table 3. The successful task will be given one credit, the partially successful task will be given a half credit, and the unsuccessful task will be given zero credit. Therefore, the overall effectiveness rating of the application was calculated based on the following equation (Ismail et al., 2011):

Effectiveness $(\%)=($ Success $+($ Partial success $\times 0.5)) /$ Total $\times 100 \%=(46+(13 \times 0.5)) / 60$ $\mathrm{x} 100 \%=87.5 \%$

This means that usability testing with children has shown that the target users can use the developed application effectively at $87.5 \%$.

\section{Efficiency:}

Similarly, the overall efficiency rating of the application was calculated based on the following equation. 
Efficiency $(\%)=($ Success $+($ Partial success $\times 0.5)) /$ Total $\times 100 \%=((53+(12 \times 0.5)) / 70 \times$ $100 \%=84.3 \%$

This means that usability testing with children has confirmed that the target users can smoothly play the application's activities at $84.4 \%$.

\section{Satisfaction:}

The satisfaction questionnaire consists of 5 items. The items and answers are structured using a 3 -point Likert scale (Disagree $=1$ credit, Neutral $=2$ credits, Agree $=3$ credits). Therefore, the overall satisfaction for the application was calculated based on the following equation:

Satisfaction $(\%)=$ Answer Point $/$ Total Point $\times 100 \%=75 / 75 \times 100 \%=100 \%$.

This means that all the children felt satisfied with the developed application and enjoyed playing its activities.

Generally, the overall usability of the application was measured by calculating the average of the three usability components based on the following equation:

Usability $(\%)=($ Effectiveness + Efficiency + Satisfaction $) / 3 \times 100 \%=(87.5+84.3+100) / 3$ $\mathrm{x} 100 \%=90.6 \%$.

Hence, the children did manage to finish the application's activities completely, smoothly, and enjoyably, at $90.6 \%$.

Furthermore, a set of usability issues was identified and then solved. For example, the children could not understand the sign-up button, found the images of the faces' parts in the Faces activity small in size, and the narrating option distracted them.

The usability issues were fixed, and the application has become ready to be applied on a sample of children to assess the perceived experience during the training period and their WM performance.

\subsection{Evaluating the children's Perceived Experience (UX)}

The usability survey and the unstructured observation were utilized to assess the children's perceived experience during the training period:

\subsubsection{Usability survey}

The closed \& open-ended usability survey was employed to evaluate the children's experience following engaging with the application:

Regarding the validation and reliability of the closed-ended usability survey, the survey's content was validated by a set of professionals in educational technology and HCI (4 researchers). 5 out of 16 items were deleted, and two items were reworded to be understandable for children. By using the psych package in R (Revelle, 2020), the survey achieved a substantial reliability degree with a Cronbach's alpha $(\alpha)$ : 0.91 and Omega Polychoric covariance matrix: 0.95, which suggests that the closed-ended survey is consistent and acceptable in assessing the children's perceived experience with the developed application.

As detailed in Table 4, the results of applying the closed-end survey indicated that most children (86.5\%) had a good experience with the training application, as compared to just $5 \%$ who did not have that.

Concerning the application's design, more than $90 \%$ of children reported that the navigation across the application was easy, and the application is visually appealing. Similarly, most children reported that their friends would like to play this application and use three images as a password to $\log$ in to the application. This means that using a visual password was helpful because it mitigated the burden of creating and memorizing text passwords.

Regarding the application's activities, most children enjoyed playing the activities, and they liked the story of the application as a contest to get the treasure. This suggests that employing the meaningful story (treasure hunt), in the form of a contest with the virtual competitor (the pirate), as a 
Table 4. The children's responses on the close-ended Usability Questionnaire

\begin{tabular}{|c|c|c|c|c|c|c|}
\hline $\mathbf{N}$ & Items & $\underset{(1)}{\text { Disagree }}$ & $\stackrel{\bullet}{-}$ Neutral (2) & $\begin{array}{l}\text { (i.) } \\
\text { Agree (3) }\end{array}$ & Mean & SD \\
\hline \multicolumn{7}{|c|}{ Designing the application } \\
\hline 1 & $\begin{array}{l}\text { The games page } \\
\text { (home page) } \\
\text { interface is easy to } \\
\text { navigate }\end{array}$ & $8 \%$ & $0 \%$ & $92 \%$ & 2.83 & 0.58 \\
\hline 2 & $\begin{array}{l}\text { The treasure } \\
\text { application is } \\
\text { visually appealing }\end{array}$ & $0 \%$ & $8 \%$ & $92 \%$ & 2.92 & 0.29 \\
\hline 3 & $\begin{array}{l}\text { I think my friends } \\
\text { would like to play } \\
\text { this application's } \\
\text { games }\end{array}$ & $8 \%$ & $8 \%$ & $83 \%$ & 2.75 & 0.62 \\
\hline 4 & $\begin{array}{l}\text { Using three images } \\
\text { as a password eased } \\
\text { to log in to the } \\
\text { application }\end{array}$ & $8 \%$ & $8 \%$ & $83 \%$ & 2.75 & 0.62 \\
\hline 5 & $\begin{array}{l}\text { It was easy to } \\
\text { learn to use the } \\
\text { application }\end{array}$ & $8 \%$ & $25 \%$ & $67 \%$ & 2.58 & 0.67 \\
\hline \multicolumn{7}{|c|}{ Application's Activities } \\
\hline 6 & $\begin{array}{l}\text { I enjoy playing the } \\
\text { games }\end{array}$ & $0 \%$ & $8 \%$ & $92 \%$ & 2.92 & 0.29 \\
\hline 7 & $\begin{array}{l}\text { I like the story of } \\
\text { the application as } \\
\text { a contest to get the } \\
\text { treasure }\end{array}$ & $0 \%$ & $8 \%$ & $92 \%$ & 2.92 & 0.29 \\
\hline 8 & $\begin{array}{l}\text { The games were } \\
\text { too hard to play } \\
\text { (negative item). }\end{array}$ & $83 \%$ & $8 \%$ & $8 \%$ & 2.75 & 0.62 \\
\hline \multicolumn{7}{|c|}{ Feedback and Instructions } \\
\hline 9 & $\begin{array}{l}\text { The training video, } \\
\text { before each game, } \\
\text { helped me how to } \\
\text { play the games. }\end{array}$ & $0 \%$ & $8 \%$ & $92 \%$ & 2.92 & 0.29 \\
\hline 10 & $\begin{array}{l}\text { I think the parrot's } \\
\text { voice is clear and } \\
\text { friendly. }\end{array}$ & $0 \%$ & $8 \%$ & $92 \%$ & 2.92 & 0.29 \\
\hline 11 & $\begin{array}{l}\text { Positive feedback } \\
\text { such as excellent, } \\
\text { good work... } \\
\text { motivated me to } \\
\text { keep playing }\end{array}$ & $17 \%$ & $0 \%$ & $83 \%$ & 2.67 & 0.78 \\
\hline
\end{tabular}

game element motivated the trainees to engage in the training. On the other side, only $8 \%$ of children stated that it was too hard to play the application's activities.

In terms of the feedback and instructions, more than $90 \%$ of children agreed that the training video before each activity was helpful, and the parrot voice was friendly and clear. This indicates good design with an appropriate gamification element (e.g., virtual helper) can be beneficial for those children, and provide them with instant support during the learning process could be helpful. Similarly, more than $80 \%$ of children reported that the positive feedback provided throughout the 
training helped them to keep playing the application's activities. This goes in line with the results of Farr \& Lind (2019), which indicated that the continuity of the employees' intention to work is expected to boost by increasing the motivating language.

These results taken together indicate that the training application is developed with relevant support, is well-designed and appropriate to train, motivate and engage those children.

Regarding the content validity of the Interview-Based questionnaire, only a question: "what are the most attractive features in the treasure application?" was reworded to "what games do you like to play? Why?

The interview-based questionnaire was conducted, and the responses were analyzed to assess the children's perceived experience over the five-week training period as follow:

The interview-based questionnaire was transcribed and then analyzed using the thematic analysis research method (using Nvivo 12). In total, 133 codes were applied to data under four global themes to summarize the five questions of the interview. The Four global themes are preferred activities, unpreferred activities, the best thing about the application, and suggestions for improving the application.

In terms of the preferred activities, as shown in Figure 3, it is obvious that all the children (100\%) liked the Numbers activity the most. More than three-quarters of children reported that they like the Compass, Map, Tools, and Faces activities. By contrast, only $40 \%$ of children liked the Letters activity.

Regarding the un-preferred activities, more than half of the children did not like the Letters activity, $17 \%$ did not like the Faces and the Tools activities, and only $8 \%$ did not prefer both the Map and Compass activities.

The children reported that the most encouraging aspect was their trials to get the treasure. Finally, they suggested that the Letters activity must be modified to be easier to play and proposed 3 solutions; reducing the number of letters needed to be remembered and recalled or recalling the letters in order instead of reverse order or swapping the letters with numbers.

\subsubsection{Unstructured observation}

The unstructured observation method was employed to assess the children's engagement and hence, the user-perceived experience over the training period (5 weeks).

The unstructured observation was transcribed and then analyzed using the thematic analysis research method (using the Nvivo 12). In total, 99 codes were applied to data under three global themes to summarize the unstructured observation report. The three global themes are activities found to be easy, activities found too difficult, and strategies.

As shown in Figure 4, it is obvious that all the children (100\%) played the Map and Compass activities easily, $92 \%$ and $75 \%$ of children played the Faces and Numbers activities smoothly, and nearly $70 \%$ of children found the Tools activity was easy to be played. This is because the children considered themselves in a contest with the pirate, which encouraged them to play hard to get the treasure.

Conversely, all the children struggled to play the Letters activity, particularly the higher levels, because they failed to repeat the letters in reverse order, some of them used to recall the letters in order, and some of them could lose their patience while listening to the letters. It was also noticed that narrating the letters distracted some children during playing. Similarly, 33\% of children found difficulties in playing Tools activity because they were found to be impulsive during memorizing the places of images, particularly while playing the higher levels.

At the beginning of the training, 25\% of children found it difficult to play the Numbers activity because they struggled to differentiate between the smallest and the biggest numbers or put them in order. Therefore, they were supported by watching some tutorial videos on how to sort numbers in order during the training period. Similarly, one of the children could not identify the directions of the Compass activity, so the child was advised to watch some embedded training videos (the simulated examples prior to each activity). 
Figure 3. The results of analyzing the interview.

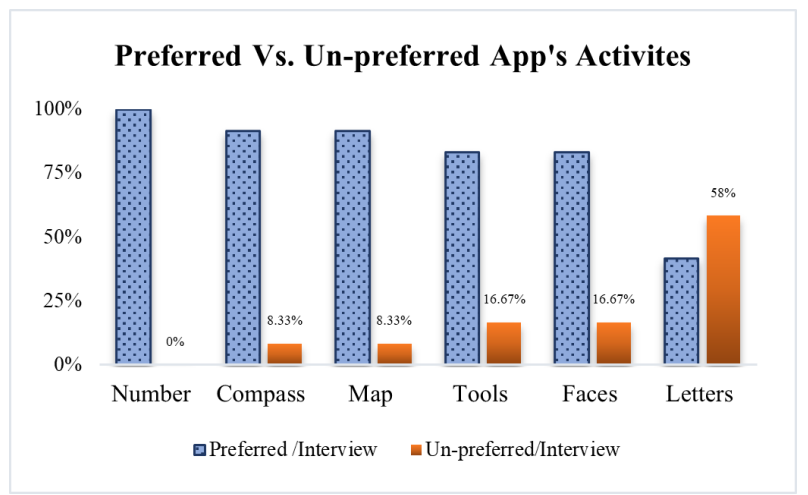

Figure 4. The results of analyzing the observation.

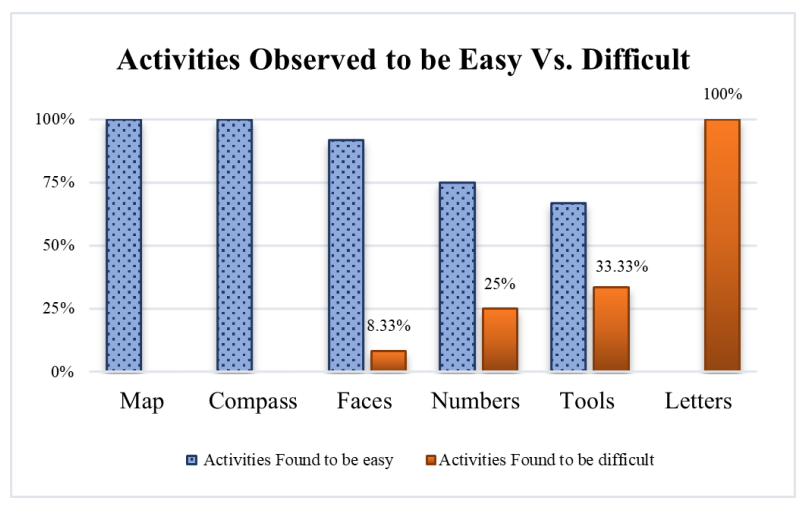

Hence, it is recommended that those particular learning groups be provided with a quiet learning environment. At least, minimizing the background noise is favorable to avoid distraction easily.

\subsection{Evaluating the Children's WM Performance}

In order to evaluate the impact of the training application on improving the children's WM performance, the verbal and non-verbal WM tests of the Stanford-Binet Intelligence Scale (Fifth Edition) as a standardized test were applied before and after the training period. The Wilcoxon Signed-Rank Test revealed that the engagement with the developed application produced a statistically significant improvement in the verbal $(\mathrm{Z}=3.074, \mathrm{p}<0.05)$ and non-verbal $(\mathrm{Z}=3.106, \mathrm{p}<0.05) \mathrm{WM}$ performance of children with LDs with a medium effect size (0.63).

Similarly, the results of the verbal and non-verbal WM tests of the Stanford-Binet Intelligence Scale were also compared, as shown in Figure 5. Obviously, all the children's verbal and non-verbal WM performance was improved after engaging in the training period, and this improvement was better in verbal than non-verbal WM performance. This can be illustrated by the improvements in both verbal and non-verbal WM capacity due to the nature of the developed application, which encompasses six activities targeting the different components of the WM. Another explanation could be that most of the experimental group have problems in the phonological loop (one component of the working memory), evidenced by their lower verbal WM pre-test scores as compared to the non-verbal scores as well as some studies, such as Maehler and Schuchardt (2016), revealed that children diagnosed 
Figure 5. The children's verbal \& non-verbal WM performance before and after the training.

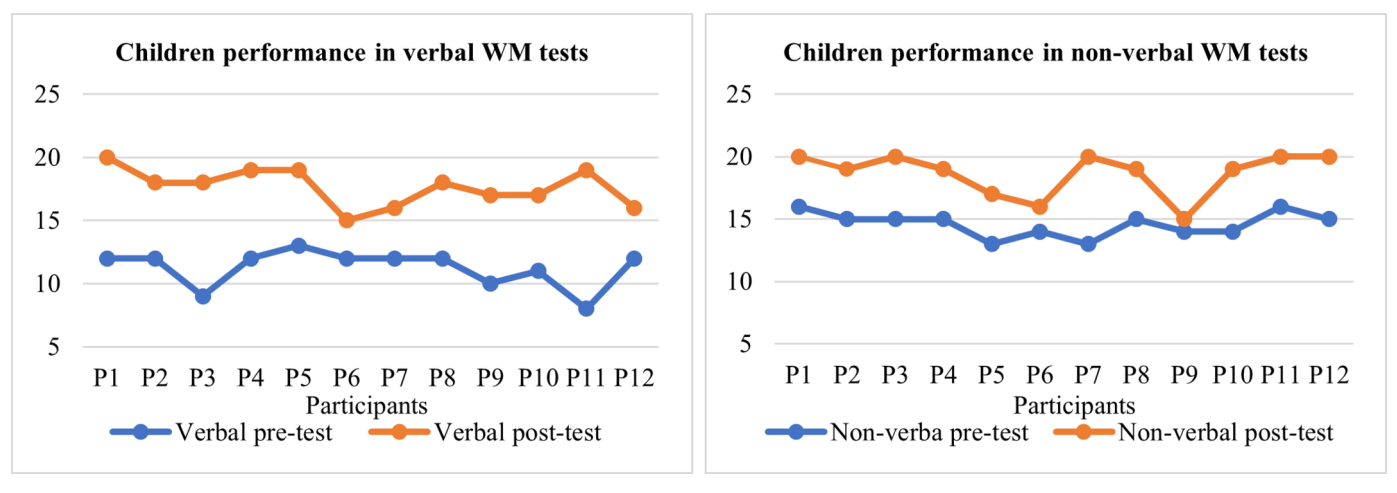

with dyslexia show deficits in phonological processing and storage. Swanson \& Berninger (1996) indicated that children with all types of LDs exhibit poor WM performance, particularly in verbal and executive WM. Therefore, by training, the improvement was better in the verbal WM capacity, which is the weakest aspect of the WM of the experimental sample group.

\section{CONCLUSION}

The current study employed the DBR approach to design, develop, evaluate, and improve a cognitive training application for children with LDs. The DBR's framework consists of two design iterations. In the first iteration, an interactive prototype was designed, in light of a set of 15 guidelines suggested by the researchers, after addressing the characteristics of the target users and reviewing some learning theories. The prototype involved 6 activities to training different WM components and was evaluated by 12 experts. The results of the expert review revealed that the guidelines are consistently applied at $84.6 \%$, and a set of amendments was performed to improve the usability of the developing application.

In the second iteration, the prototype was developed into a full application and its usability testing was performed on five children with LDs to explore any usability issues before implementing the application on the experimental group. The usability user testing results revealed that the children managed to finish the application's activities completely, smoothly, and enjoyably, at $90.6 \%$. The application was applied to a sample of 16 children with LDs continuously to assess the entire perceived experience during the training and evaluate their WM performance after the training. The children's verbal and no-verbal WM performance was improved significantly after the training period, and most of the children (86.5\%) had a good experience with the application. However, some children had some difficulties while playing the Letters and the Numbers activities. Consequently, some suggestions were outlined to tackle those difficulties.

Furthermore, this study presents a free bilingual application to train the WM capacity of children with LDs, which could aid many families who cannot bear the costs' burden of the WM commercial applications. The case study was focused on the Arabic culture. However, the lessons learned can be transferrable to children with learning disabilities of different ethnic backgrounds. Our work is suitable and making research contributions to the community, since we provide a framework with clear guidelines, case studies and a summary of recommendations.

Finally, the evaluation outcomes could also help other developers and designers wishing to develop more engaging cognitive applications, as follows.

- The current study recommends adopting the DBR to systematically develop effective cognitive training applications for children with LDs because it enables the designer to identify and tackle 
usability problems. Therefore, the DBR framework presented in this study can be used as a guide for designing and developing such applications, particularly this framework includes a set of practical guidelines.

- During designing the applications for children with LDs, the designers should carefully choose the appropriate game elements not to tax the WM capacity or negatively influence the trainee's performance. For example, the designer can choose a meaningful story to keep all activities interrelated, and as a result, motivate the children, as well as embedding an internal competition (virtual competitor, acts as an intrinsic motivator) is highly recommended to maintain an appropriate level of motivation and competition compared to using the external competition with other players who cause anxiety and consequently increase the cognitive load level.

- It is recommended that while designing verbal activities to use numbers rather than letters because letters are difficult to be memorized particularly in reverse order.

- Based on the results of the unstructured observation, those children could be supported via some strategies, in the form of a tutorial video, to encourage them to find their own way (strategy) to enhance their performance during training. For example, using their hands with each finger representing one item to memorize a set of items or repeating those items can be used to repeat the items in the form of a rhythm, etc. These strategies could be transferred to their daily learning situations. These observations go in line with using external- memory tools such as a physical scratchpad to help children overcome their working memory limits (Budiu, 2018).

To conclude, the cognitive training applications designed specifically for children with LDs have to consider their needs and characteristics and should be designed based on practice guidelines to engage the children, improve their perceived UX, and enhance their WM performance.

\section{Future Research}

The developed application can be applied to a bigger sample group of children with LDs to examine further the effect of the application on improving the WM performance and assess if the effect of the training on this application can be transferred to other cognitive abilities.

\section{ACKNOWLEDGMENT}

This project is partly supported by VC Research (VCR 0000143) for Prof Chang. 


\section{REFERENCES}

Abdou, D., \& Jasimuddin, S. M. (2020). The Use of the UTAUT Model in the Adoption of E-Learning Technologies: An Empirical Study in France Based Banks. Journal of Global Information Management, 28(4), 38-51. doi:10.4018/JGIM.2020100103

Alloway, T. P., Gathercole, S. E., Kirkwood, H., \& Elliott, J. (2009). The cognitive and behavioral characteristics of children with low working memory. Child Development, 80(2), 606-621. doi:10.1111/j.1467-8624.2009.01282.x PMID:19467014

Baddeley, A. (2000). The episodic buffer: A new component of working memory? Trends in Cognitive Sciences, 4(11), 417-423. doi:10.1016/S1364-6613(00)01538-2 PMID:11058819

Boyle, C. A., Boulet, S., Schieve, L. A., Cohen, R. A., Blumberg, S. J., Yeargin-Allsopp, M., Visser, S., \& Kogan, M. D. (2011). Trends in the prevalence of developmental disabilities in US children, 1997-2008. Pediatrics, 127(6), 1034-1042. doi:10.1542/peds.2010-2989 PMID:21606152

Brown, A. L. (1992). Design Experiments: Theoretical and Methodological Challenges in Creating Complex Interventions in Classroom Settings. Journal of the Learning Sciences, 2(2), 141-178. Advance online publication. doi:10.1207/s15327809j1s0202_2

Budiu, R. (2018). Working Memory and External Memory. Nielsen Norman Group. https://www.nngroup.com/ articles/working-memory-external-memory/

Chen, X., Ye, M., Chang, L., Chen, W., \& Zhou, R. (2017). Effect of Working Memory Updating Training on Retrieving Symptoms of Children With Learning Disabilities. Journal of Learning Disabilities. Advance online publication. doi:10.1177/0022219417712015 PMID:28597718

Department for Education-UK. (2016). Special educational needs in England: January 2016. https://www.gov. uk/government/uploads/system/uploads/attachment_data/file/539158/SFR29_2016_Main_Text.pdf

Department for Education-UK. (2018). Special educational needs in England: January 2018. https://assets. publishing.service.gov.uk/government/uploads/system/uploads/attachment_data/file/729208/SEN_2018_Text.pdf

Dichev, C., \& Dicheva, D. (2017). Gamifying education: What is known, what is believed and what remains uncertain: a critical review. International Journal of Educational Technology in Higher Education, 14(1), 9. doi:10.1186/s41239-017-0042-5

Farag, S. (2011). The Stanford-Binet Intelligence Scales, Fifth Edition-Arab Standards. Anglo-Egyptian Bookshop. https://www.anglo-egyptian.com/ar/book.php?id=13180

Farr, L., \& Lind, M. (2019). Motivating Language and Intent to Stay in a Backsourced Information Technology Environment. Journal of Global Information Management, 27(3), 1-18. doi:10.4018/JGIM.2019070101

Gathercole, S. (2009). Identifying and supporting children with working memory problems memory problems [Workshop presentation]. 12h Annual Residential SEN Conference 2009 Individual Needs, University of York. http://www.learning-works.org.uk/susan-gathercole-workshop-1-pdf

Gupta, P. K., \& Sharma, D. V. (2017). Working Memory and Learning Disabilities: A Review. International Journal of Indian Psychology, 4(4). Advance online publication. doi:10.25215/0404.013

Ismail, M., Diah, N. M., Ahmad, S., Kamal, N. A. M., \& Dahari, M. K. M. (2011). Measuring usability of educational computer games based on the user success rate. 2011 International Symposium on Humanities, Science and Engineering Research, 56-60. doi:10.1109/SHUSER.2011.6008500

Jen, E., Moon, S., \& Samarapungavan, A. (2015). Using Design-Based Research in Gifted Education. Gifted Child Quarterly, 59(3), 190-200. Advance online publication. doi:10.1177/0016986215583871

Katz, B., Jaeggi, S., Buschkuehl, M., Stegman, A., \& Shah, P. (2014). Differential effect of motivational features on training improvements in school-based cognitive training. Frontiers in Human Neuroscience, 8. Advance online publication. doi:10.3389/fnhum.2014.00242 PMID:24795603

Kennedy-Clark, S. (2013). Research by Design: Design-Based Research and the Higher Degree Research student. Journal of Learning Design, 6(2), 26-32. doi:10.5204/jld.v6i2.128 
Klingberg, T., Fernell, E., Olesen, P. J., Johnson, M., Gustafsson, P., Dahlström, K., Gillberg, C. G., Forssberg, H., \& Westerberg, H. (2005). Computerized Training of Working Memory in Children With ADHD-A Randomized, Controlled Trial. Journal of the American Academy of Child and Adolescent Psychiatry, 44(2), 177-186. doi:10.1097/00004583-200502000-00010 PMID:15689731

Lumsden, J., Edwards, E. A., Lawrence, N. S., Coyle, D., \& Munafò, M. R. (2016). Gamification of Cognitive Assessment and Cognitive Training: A Systematic Review of Applications and Efficacy. JMIR Serious Games, 4(2), e11. doi:10.2196/games.5888 PMID:27421244

MacCormack, J., \& Matheson, I. (2015). Understanding Working Memory and Learning Disabilities. LD@ school. https://www.ldatschool.ca/understanding-working-memory-and-lds/

Maehler, C., \& Schuchardt, K. (2016). Working memory in children with specific learning disorders and/or attention deficits. Learning and Individual Differences, 49, 341-347. doi:10.1016/j.lindif.2016.05.007

Mahncke, H. W., Connor, B. B., Appelman, J., Ahsanuddin, O. N., Hardy, J. L., Wood, R. A., Joyce, N. M., Boniske, T., Atkins, S. M., \& Merzenich, M. M. (2006). Memory enhancement in healthy older adults using a brain plasticity-based training program: A randomized, controlled study. Proceedings of the National Academy of Sciences of the United States of America, 103(33), 12523-12528. doi:10.1073/pnas.0605194103 PMID:16888038

Marcelle, E. T., Ho, E. J., Kaplan, M. S., Adler, L. A., Castellanos, F. X., \& Milham, M. P. (2018). Cogmed Working Memory Training Presents Unique Implementation Challenges in Adults With ADHD. Frontiers in Psychiatry, 9, 388. Advance online publication. doi:10.3389/fpsyt.2018.00388 PMID:30210370

McFarland, J., Hussar, B., Zhang, J., Wang, X., Wang, K., Hein, S., Diliberti, M., Cataldi, E. F., Mann, F. B., Barmer, A., Nachazel, T., Barnett, M., \& Purcell, S. (2019). The Condition of Education 2019. US Department of Education. Washington, DC: National Center for Education Statistics, NCES 2019-144, 396.

Melby-Lervåg, M., \& Hulme, C. (2013). Is working memory training effective? A meta-analytic review. Developmental Psychology, 49(2), 270-291. doi:10.1037/a0028228 PMID:22612437

Mencap. (2021). Learning difficulties. Mencap. https://www.mencap.org.uk/learning-disability-explained/ learning-difficulties

Nebel, S., Schneider, S., \& Rey, G. D. (2016). From duels to classroom competition: Social competition and learning in educational videogames within different group sizes. Computers in Human Behavior, 55, 384-398. doi:10.1016/j.chb.2015.09.035

Nielsen, J. (2000). Ecommerce UX Research Report (4th ed.). https://www.nngroup.com/reports/ecommerceuser-experience/

Nielsen, J. (2012). How Many Test Users in a Usability Study? Nielsen Norman Group. https://www.nngroup. com/articles/how-many-test-users/

Ninaus, M., Pereira, G., Stefitz, R., Prada, R., Paiva, A., Neuper, C., \& Wood, G. (2015). Game elements improve performance in a working memory training task. International Journal of Serious Games, 2(1). Advance online publication. doi:10.17083/ijsg.v2i1.60

Peijnenborgh, J. C. A. W., Hurks, P. M., Aldenkamp, A. P., Vles, J. S. H., \& Hendriksen, J. G. M. (2016). Efficacy of working memory training in children and adolescents with learning disabilities: A review study and meta-analysis. Neuropsychological Rehabilitation, 26(5-6), 645-672. doi:10.1080/09602011.2015.10263 56 PMID:25886202

Peng, P., \& Fuchs, D. (2016). A Meta-Analysis of Working Memory Deficits in Children With Learning Difficulties: Is There a Difference Between Verbal Domain and Numerical Domain? Journal of Learning Disabilities, 49(1), 3-20. doi:10.1177/0022219414521667 PMID:24548914

Revelle, W. (2020). psych: Procedures for Psychological, Psychometric, and Personality Research (2.0.7) [Computer software]. https://CRAN.R-project.org/package=psych

Roberts, G., Quach, J., Spencer-Smith, M., Anderson, P. J., Gathercole, S., Gold, L., Sia, K.-L., Mensah, F., Rickards, F., Ainley, J., \& Wake, M. (2016). Academic Outcomes 2 Years After Working Memory Training for Children With Low Working Memory: A Randomized Clinical Trial. JAMA Pediatrics, 170(5), e154568. doi:10.1001/jamapediatrics.2015.4568 PMID:26954779 
Saputra, M. R. U. (2015). LexiPal: Design, Implementation and Evaluation of Gamification on Learning Application for Dyslexia. International Journal of Computers and Applications, 131(7), 37-43. doi:10.5120/ ijca2015907416

Seo, Y.-J., \& Woo, H. (2010). The identification, implementation, and evaluation of critical user interface design features of computer-assisted instruction programs in mathematics for students with learning disabilities. Academic Press.

Sinnari, D. T. (2019). Guidelines to Assist Building Effective Educational Applications And E-Games for Children With ADHD [Doctor of philosophy, University of Surrey]. http://epubs.surrey.ac.uk/850159/1/Doaa\%20 Sinnar\%20Phd\%20Thesis\%20-\%202019.pdf

Swanson, H. L., \& Berninger, V. W. (1996). Individual differences in children's working memory and writing skill. Journal of Experimental Child Psychology, 63(2), 358-385. doi:10.1006/jecp.1996.0054 PMID:8923751

Swanson, H. L., \& Sáez, L. (2003). Memory Difficulties in Children and Adults with Learning Disabilities. In H. L. Swanson, K. R. Harris, \& S. Graham (Eds.), Handbook of Learning Disabilities. The Guilford Press.

Turan, Z., Avinc, Z., Kara, K., \& Goktas, Y. (2016). Gamification and Education: Achievements, Cognitive Loads, and Views of Students. International Journal of Emerging Technologies in Learning, 11(07), 64-69. doi:10.3991/ijet.v11i07.5455

Wong, A. S., He, M. Y., \& Chan, R. W. (2014). Effectiveness of computerized working memory training program in Chinese community settings for children with poor working memory. Journal of Attention Disorders, 18(4), 318-330. doi:10.1177/1087054712471427 PMID:23382580

Xanthidis, D., \& Xanthidou, O. K. (2021). A Proposed Framework for Developing an Electronic Medical Record System. Journal of Global Information Management, 29(4), 78-92. doi:10.4018/JGIM.20210701.oa4

Zhang, H., Chang, L., Chen, X., Ma, L., \& Zhou, R. (2018). Working Memory Updating Training Improves Mathematics Performance in Middle School Students With Learning Difficulties. Frontiers in Human Neuroscience, 12, 154. Advance online publication. doi:10.3389/fnhum.2018.00154 PMID:29740298

Zisimopoulos, D. A., \& Galanaki, E. P. (2009). Academic Intrinsic Motivation and Perceived Academic Competence in Greek Elementary Students with and without Learning Disabilities. Learning Disabilities Research \& Practice, 24(1), 33-43. doi:10.1111/j.1540-5826.2008.01275.x

Victor Chang is a Professor of Data Science and IS at Teesside University, UK. He was a Senior Associate Professor, Xi'an Jiaotong-Liverpool University between June 2016 and Aug 2019. He was a Senior Lecturer at Leeds Beckett University, UK between Sep 2012 and May 2016. Within 4 years, he completed Ph.D. (CS, Southampton) and PGCert (HE, Fellow, Greenwich) while working for several projects. Before becoming an academic, he achieved $97 \%$ on average in 27 IT certifications. He won an IEEE Outstanding Service Award in 2015, best papers in 2012, 2015 \& 2018, 2016 European award: Best Project in Research, 2017 Outstanding Young Scientist and numerous awards since 2012. He is widely regarded as a leading expert on Big Data/Cloud/loT/security. He is a visiting scholar/PhD examiner at several universities, an Editor-in-Chief of IJOCI \& OJBD, former Editor of FGCS, Associate Editor of TII \& Info Fusion, founding chair of international workshops and founding Conference Chair of loTBDS, COMPLEXIS, FEMIB \& IIOTBDSC. He was involved in projects worth more than £13 million in Europe and Asia. He published 3 books and edited 2 books. He gave 18 keynotes internationally as a top researcher.

Andrew Bingham looked into ways of enhancing student learning of Requirements Engineering in the Web Engineering field. He designed and built a Computer Aided Web Engineering (CAWE) tool - which is now used by students worldwide and has been updated recently to reflect App development for touch devices. Andrew joined the Web Engineering Research group within the School of Computing and this is where a seed project was shaped into a PhD proposal. He delivered a number of conference papers as part of enhancing the intervention. The intervention developed from a paper based method to a more fully fledged framework supported by a dedicated learning environment. He undertook three main cycles of research over seven years, firstly by reviewing the literature in the area of Requirements Engineering (RE) and Web Engineering (WE). As the framework focused on learning, \& NBSP; he also looked at pedagogical learning theory centred on the computing discipline. In each cycle, a framework was designed, released to students for use in their learning, evaluated and modified before the release in the next cycle. Andrew continues to support students working on their RE within new fields of development, including mobile app development. 